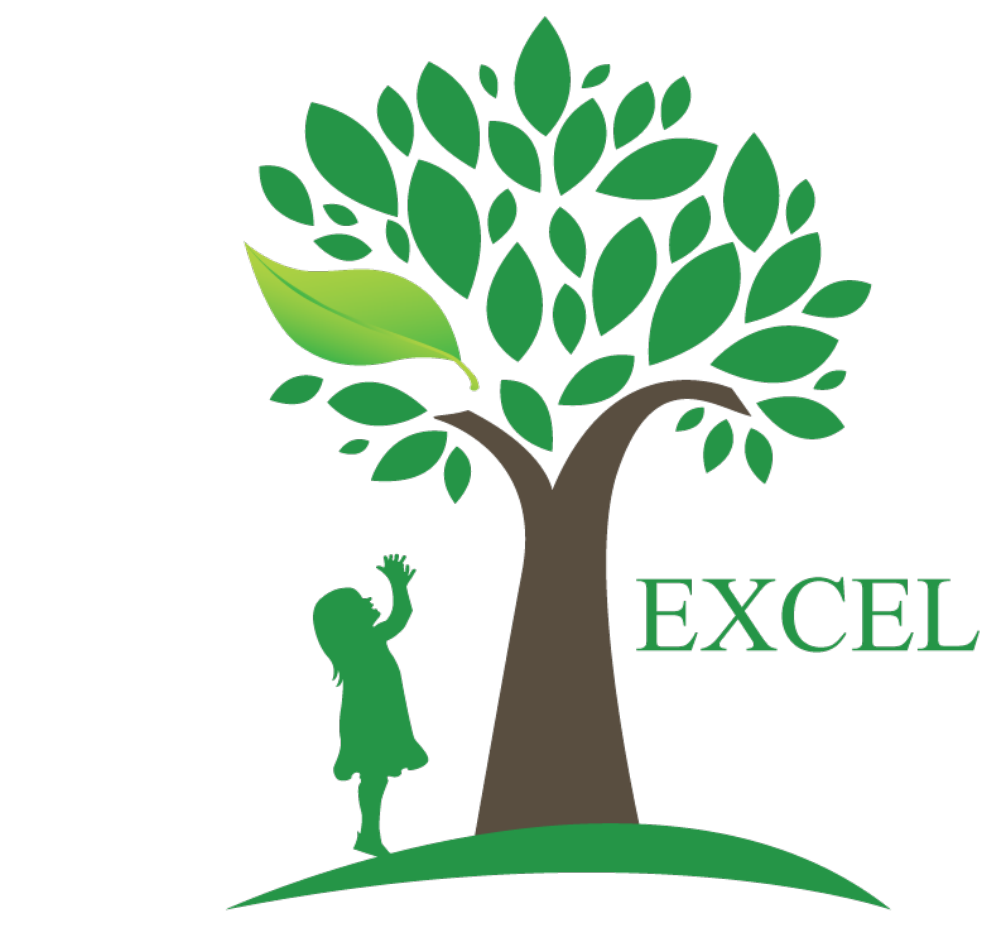

\title{
Importance of Relationships
}

Prepared by

\author{
Vanessa Ibarra \\ Vanessa.ibarra2@unt.edu
}

June 26, 2014

This material was produced for Excellence in Curricula and Experiential Learning (EXCEL) Program, which is funded through UNT Sustainability. The University of North Texas holds the copyright. This material is available for use under a Creative Commons Attribution-NonCommercial 3.0 Unported License.

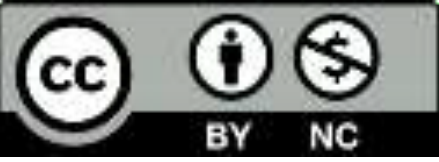




\begin{tabular}{|c|c|}
\hline \multicolumn{2}{|r|}{ Document Information } \\
\hline Title & Family and Generations \\
\hline Prepared By & UNT Sustainability \\
\hline Original Creation Date & June 26, 2014 \\
\hline Version & 1.0 \\
\hline Date of Current Version & June 26, 2014 \\
\hline Revised By & \\
\hline Edited By & Heather Treadway \\
\hline Description & $\begin{array}{l}\text { A collection of activities and resources regarding the study } \\
\text { of relationships that meet state education standards and } \\
\text { national sustainability standards for the Kindergarten level. }\end{array}$ \\
\hline Rights Information & (C) University of North Texas \\
\hline Licensing Information & $\begin{array}{l}\text { (c) EY-NC } \\
\text { This work is licensed under a Creative Commons Attribution- } \\
\text { NonCommercial } 4.0 \text { International License. }\end{array}$ \\
\hline
\end{tabular}

\begin{tabular}{|l|l|}
\hline \multicolumn{2}{|c|}{ Revision History } \\
\hline Previous Version & none \\
\hline Changes & \\
\hline
\end{tabular}




\section{Importance of Relationships}

\section{Table of Contents}

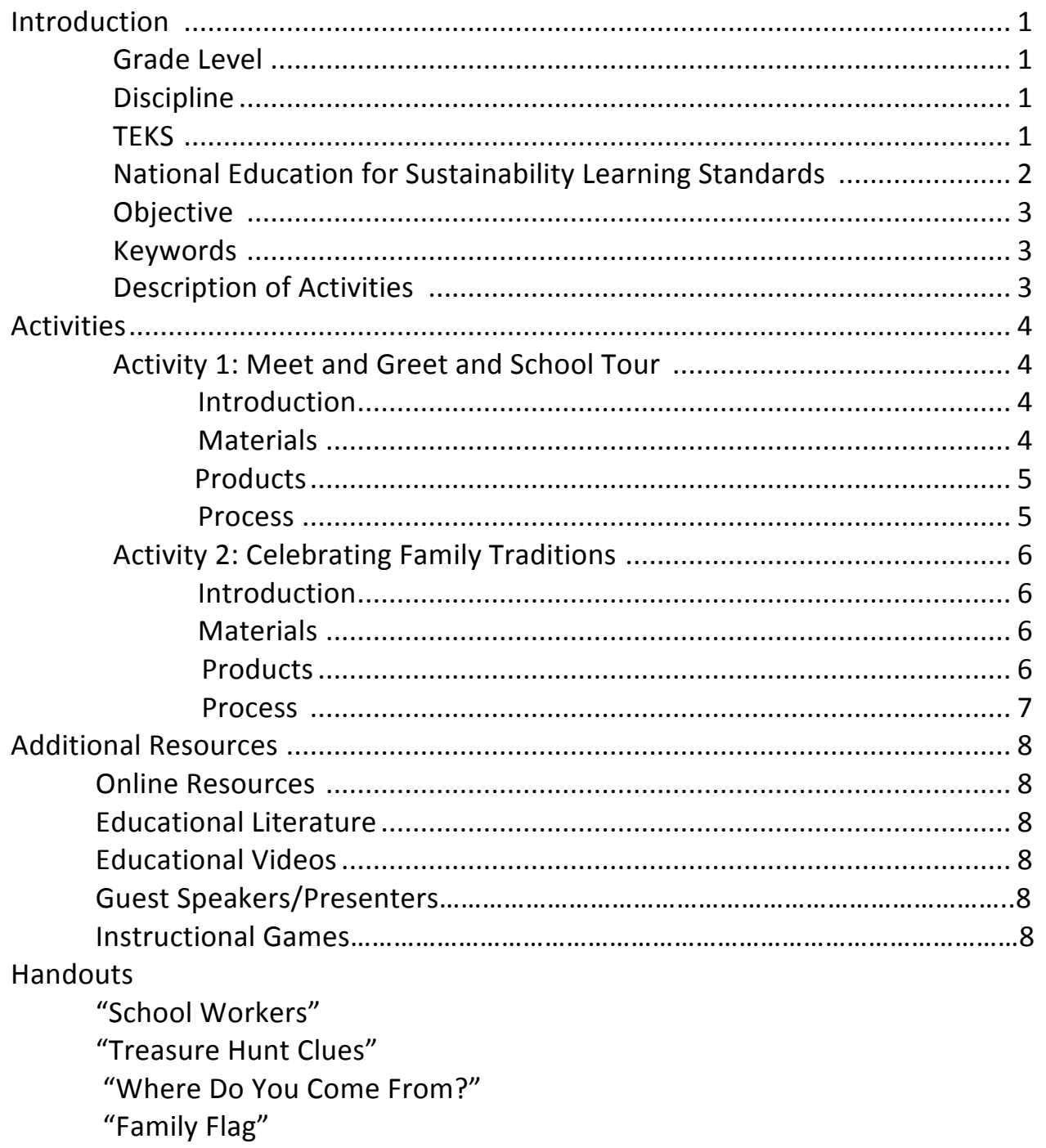

$$
1
$$
2 , 4

\section{8} .

\section{政} 8 


\section{Introduction}

\section{Grade Level}

These activities are intended for a kindergarten classroom.

\section{Discipline}

These activities have a social studies focus.

\section{TEKS}

Content:

In Kindergarten, the study of the self, home, family, and classroom establishes the foundation for responsible citizenship in society. Students explore state and national heritage by examining the celebration of patriotic holidays and the contributions of individuals. The concept of chronology is introduced. Students apply geographic concepts of location and physical and human characteristics of place. Students identify basic human needs and ways people meet these needs. Students learn the purpose of rules and the role of authority figures in the home and school. Students learn customs, symbols, and celebrations that represent American beliefs and principles and contribute to our national identity. Students compare family customs and traditions and describe examples of technology in the home and school. Students acquire information from a variety of oral and visual sources. Students practice problem-solving, decision-making, and independent-thinking skills. TEKS §113.11. Social Studies, Grade K. (a)(1)

Throughout social studies in Kindergarten-Grade 12, students build a foundation in history; geography; economics; government; citizenship; culture; science, technology, and society; and social studies skills. The content, as appropriate for the grade level or course, enables students to understand the importance of patriotism, function in a free enterprise society, and appreciate the basic democratic values of our state and nation as referenced in the Texas Education Code (TEC), $\S 28.002(\mathrm{~h})$. TEKS §113.11. Social Studies, Grade K. (a)(5)

Skills:

The student understands the concept of chronology. TEKS §113.11. Social Studies, Grade K. (b) $(3)(A)(B)$

The student understands the value of jobs. TEKS $§ 113.11$. Social Studies, Grade $K(b)(7)(A)(B)$

The student understands the role of authority figures. TEKS $§ 113.11$. Social Studies, Grade K (b)(9)(A)(B)

The student understands similarities and differences among people. TEKS §113.11. Social Studies, Grade K. (b)(11)(A).

The student understands the importance of family customs and traditions. TEKS $§ 113.11$. Social Studies, Grade K. (b)(12)(A)(B)

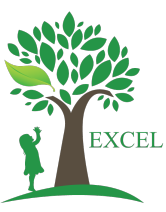


The student communicates in oral and visual forms. TEKS $§ 113.11$. Social Studies, Grade K (b) $(15)(A)(B)$

The student uses problem-solving and decision-making skills, working independently and with others, in a variety of settings. TEKS $§ 113.11$. Social Studies, Grade K. (b)(16)(A)(B)

\section{National Education for Sustainability K-12 Student Learning Standards}

$1.1 \sim$ Intergenerational Responsibility Family Generations

$2.1 \sim$ Interconnectedness $\sim$ Relationships

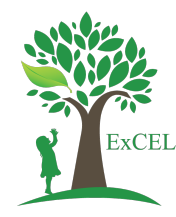




\section{Objective}

Students will learn about their new school environment and different types of family structures.

\section{Key Words}

Relationships

Generation

Traditions

Family

\section{Description of Activities}

The following activities have been compiled to address the topic of "Importance of Relationships" in kindergarten classrooms. The activities meet the state and national education standards for sixth grade, and are intended to supplement pre-existing curricula, with a focus on integrating sustainability topics. The activities can be used in conjunction or alone.

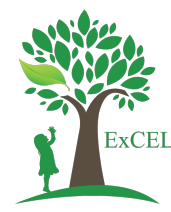




\section{Activities}

\section{Activity 1: Meet and Greet and School Tour}

\section{Introduction}

In this activity, students will lean about school and their new environment by interacting with different workers within the school and reading a poem.

\section{Materials}

Chart Paper

Handout- "School Workers"

Handout- "Treasure Hunt Clues"

School Faculty/Staff

Treasure-school supplies or books are an option

\section{Product}

Poem

Process

1. For most kindergarteners, beginning school is a very exciting time, which can also be frightening. Give students the poem and both handouts to teach them about the school workers and get them acquainted to their new surroundings.

2. Print the Handout on chart paper and laminate it. In the beginning of kindergarten, use different colors to print each word. For example, print the "A" in red and custodian in blue. Do this for the whole poem. Use the poem as a shared reading text focusing on the word, "A". Read the title. Read the poem several times with a pointer stick, pointing to each word. Teach the students that " $A$ " is very special because it is both a letter and a word! Add that "I" is as well. Model to the students how to find a word in text, by circling the first word, "A". Then, call a student forward to circle the word, "A"; continue until all of the $A$ 's are found.

3. Take a tour of the school, but remember, kindergarteners like mystery! Take advantage of this by turning the school tour into a treasure hunt.

4. Before beginning, create a schedule to speak with each person in the department about his or her "job" in the school.

- $\quad$ Next, draw a map or route to take. Then, make cards to distribute around the school; each card has a clue, which points to the next destination.

- $\quad$ The goal is to find the treasure at the end of the map.

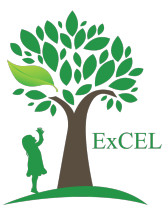


- $\quad$ The "treasure" is a school supply that student's will need for a successful school year; pencils or small books are great choices.

- Hide the treasure in the classroom and find it at the end of the school tour.

5. Begin in your classroom.

- The first card says:

- $\quad$ "We are on our way to see our school, and we begin in the nurse's room." Take students to the nurse's office to learn about the nurse's job.

- At the nurse's office, leave another clue:

- $\quad$ "If I am lost when I start the day, the secretary shows the way!" Visit the secretary's office.

6. There, have another clue:

- $\quad$ "The principal is our friend and helps to guide us to the end." Go to the principal's office.

- $\quad$ Next, visit the library. The note reads: "When we need books, the library is where we look."

- $\quad$ The next note will be, "The cafeteria is where we eat, and where new friends, we will meet."

- In the cafeteria, have another note: "The custodian helps us to clean, and we are careful when we're painting."

7. The last note will read: "Where we learn is in our classroom, and there is a treasure by the broom."

- $\quad$ Hide the treasure by the broom in the classroom for all to share.

8. After the tour. After you have the class settled in, discuss the tour and the part they liked best. Talk to the students about each worker's job and the tools they need to be successful.

9. Draw three columns on chart paper. List the school worker, the job he or she does and the tools he or she needs.

10. As a formal assessment, show the photo of the job/person. Ask who he or she is, what he or she does and the tools he or she needs to do the job. Document the results.

11. Tell the students that they too have tools that they need to be successful in the classroom and begin a discussion about classroom resources, which will lead into the next article (lesson plan) in the series about needs and wants and not wasting the resources we have.

12. After this lesson on the school workers, Kkndergarteners are more relaxed and confident. They will realize that they are a part of a bigger picture and enjoy their role in it.

Created by Bright Hub Education. Retrieved from http://www.brighthubeducation.com/pre-k-and-k-lesson-plans/45843-take-yourclass-on-school-tour-to-meet-the-school-workers/ on June 26, 2014.

Family \& Generations

(cc) BY-NC

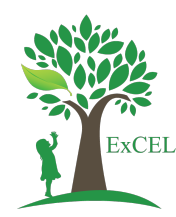




\section{Activity 2: Celebrating Family Traditions}

\section{Introduction}

Students will learn about different family traditions and holiday celebrations from around the world. And they will learn to respect similarities and differences in others, display a sense of curiosity, and meet and respect the needs of self and others.

\section{Materials}

Handout- "Where Do You Come From"

Handout- "Family Flag"

Literature

\section{Product}

Family Flag

\section{Process}

1. Day 1: Begin by showing the students several pictures of families (i.e.: family with children, new husband and wife, elderly couple, single parent with child, adoptive families (parents of a difference cultural background than the child), etc.) asking them if these pictures are or are not families.

2. Explain that a family is just not a mom, dad, and children, but that a family is a group of people who love each other and work together to take care of each other.

- Also talk about how the class is also a family because we all care about each other and are working together to become learners.

-Explain that families are all different, but are still similar in many ways.

3. To learn about the differences in the families of students in the class, send home the attached questionnaire with each child.

4. When the questionnaires are returned to school, have the child (with teacher assistance) talk about their family and where they came from, and how they celebrate different holidays and cultural celebrations.

5. Day 2: (or after several questionnaires are returned) After learning and observing the differences in the families of our class, their traditions, cultural backgrounds, and celebrations - explain that each student (and their family if you choose to send this project home to be completed) will be making a family flag to represent visually their family (using the attached template).

6. Explain to them that a crest is a symbol that represents a family, and that they get to create their own symbol that represents their family and cultural background.

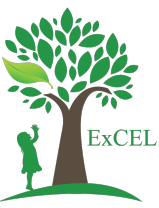


7. After completion of the project, have the students share their family flags with the class. Notice their similarities and differences, and discuss why families are different and how those differences make each person and/or family unique and special. 


\section{Additional Resources}

\section{Online Resources}

Primary Resources

http://www.brighthubeducation.com/pre-k-and-k-lesson-plans/45843-take-your-class-on-school-tour-tomeet-the-school-workers/

http://www.parents.com/kids/responsibility/values/

Secondary Resources

http://www.parents.com/parenting/better-parenting/advice/5-values-you-should-teach-your-child-byage-five/

\section{Educational Literature}

“Children Just Like Me" by Dorling Kindersley (UNICEF publication)

"World in a Supermarket" by Roseanne Lanczak Williams

"Hats Around the World" by Liza Charlesworth

"Houses" by Marcia Fries

"Mi Casa/My House" by Rebecca Emberley

"Families" by Ann Morriss

"Families are Different" by Nina Pellegrini

"Who's in a Family" by Robert Skutch and Laura Niehaus

"The Family Book" by Todd Parr

\section{Educational Video}

"People in our Community"

http://www.youtube.com/watch?v=mw6RBvUmayA

\section{Guest Speakers/Presenters}

Grandparents of the students-so they can share something about the culture of their family

Instructional Games

http://www.ehow.com/info_7992314_interactive-kindergaten-students-national-holidays.html

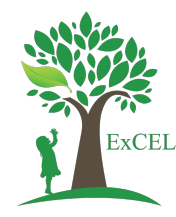




\section{School Workers}

A custodian,

A secretary,

A principal,

A librarian,

A nurse,

A cafeteria worker,

And me! 


\section{Treasure Hunt Clues}

$\begin{gathered}\text { "We are on our way to see our } \\ \text { school, and we begin in the nurse's } \\ \text { room." }\end{gathered}$
$\begin{gathered}\text { "If I am lost when I start the day, } \\ \text { the secretary shows the way!" }\end{gathered}$
"The principal is our friend and
helps to guide us to the end."
"When we need books, the library is
where we look."
"The cafeteria is where we eat, and
where new friends, we will meet."
"The custodian helps us clean, and
we are careful when we're painting."

Cards by Laurie Patsalides, all rights reserved. 
Student's Name:

\section{Where Do Your Come From?}

Our class is learning about families and their traditions. Please take a few moments and fill out this questionnaire about your family and return it to school by

How and why did your family come to America?

What country did your family come from?

What are some of your family customs or traditions?

What holidays do you celebrate?

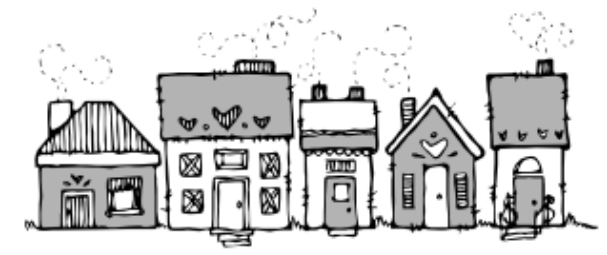


Family Flag

\begin{tabular}{|l|}
\hline Family Crest \\
\hline Name: \\
\hline Celebration or Holiday \\
\hline
\end{tabular}




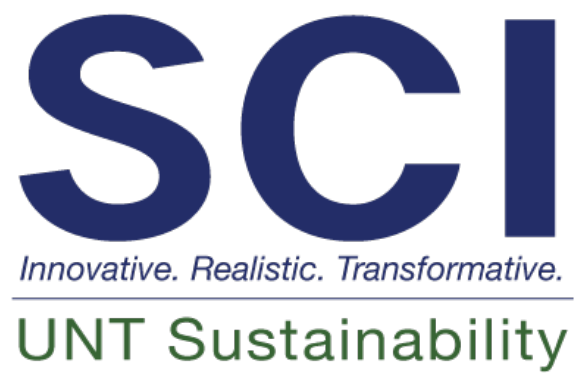

EXCEL is a division of the Sustainable Communities Initiative

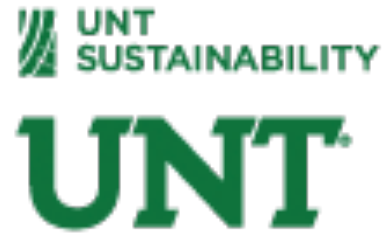

